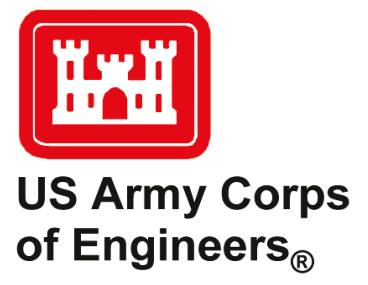

\title{
Methodology Supporting Civil Works Implementation of Tainter Gate Trunnion Friction Structural Health Monitoring
}

by Matthew D. Smith and Travis B. Fillmore

PURPOSE: The purpose of this Coastal and Hydraulics Engineering Technical Note (CHETN) is to provide guidance on the applicability of trunnion friction monitoring at navigation dams with Tainter gates.

BACKGROUND: The U.S. Army Corps of Engineers (USACE), as part of its Civil Works mission, operates and maintains approximately 700 dams. These dams provide many U.S. benefits including flood protection, water supply, hydropower, recreation, fish and wildlife conservation, and inland waterway navigation capability. The USACE dam portfolio averages over 50 years of age, and over half of the USACE-managed dams have exceeded their design service life. Currently, available funding is less than that needed to fully repair the dam portfolio. It is crucial that USACE direct repair funding and efforts at the most critical infrastructure to maximize safety and national benefit. Structural health monitoring (SHM) techniques can be used to help identify opportunities for just-in-time maintenance and repair.

A key component for many dams is spillway gates, which control the release of water from a dam. Tainter gate trunnions must be relatively free of friction, or the lifting of the gate may overstress, or fatigue, elements or connections within the end frames. Trunnion friction has been documented as the cause of a spillway gate failure at Folsom Dam in California in 1995. Spillway gate failure may lead to downstream flooding and loss of dam pool. Either of these consequences may cause significant loss of life, damage to public and private property, damage to ecosystems, loss of hydropower availability, loss of local benefits associated with the water reservoir, or loss of river navigability. It is very important for USACE to be aware of friction within the trunnion bearings with sufficient notice such that appropriate actions may be taken to prevent catastrophic failures. Thus, researchers at the U.S. Army Engineer Research and Development Center (ERDC) have been developing a methodology to detect trunnion friction using SHM techniques. This document describes a risk-informed process by which USACE Civil Works navigation projects have been screened for the potential of trunnion friction monitoring to reduce risk.

\section{METHODS}

Trunnion Friction Monitoring Methodology. It is difficult to directly measure the friction in a trunnion hub. It is believed this friction will result in a rotational resistance between the trunnion pin and trunnion bearings due to hydrostatic loading, which can be thought of as an externally applied moment, $M$, on the end-frame (Figure 1). Many end frames are constructed using a truss-like structure with steel I-beams connected by using welded joints coming together at truss panel points. 


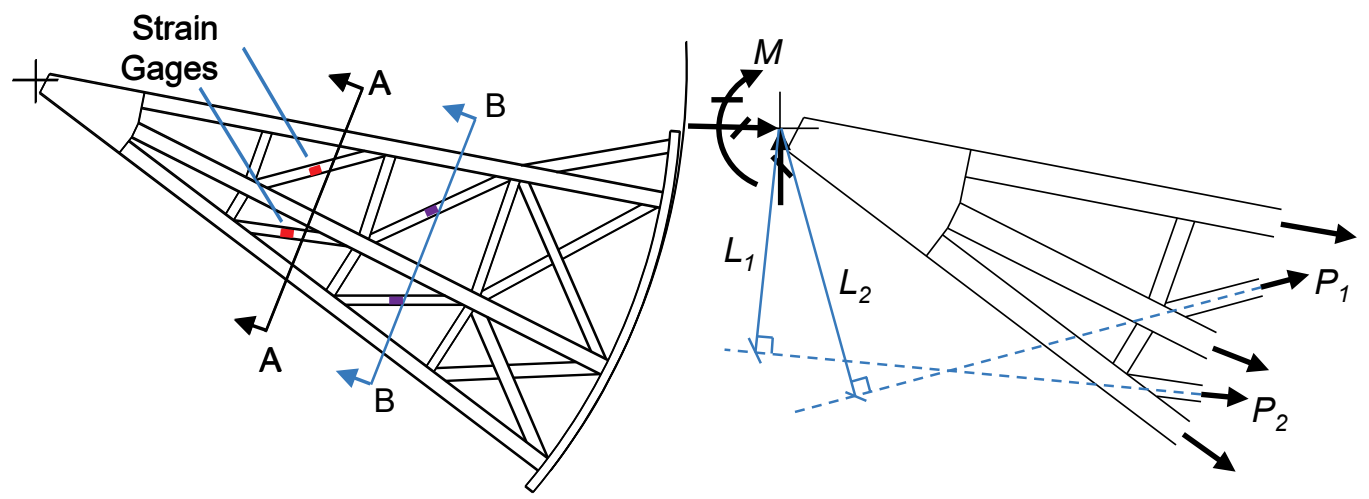

Figure 1. (a) Strut arm gages and section cut and (b) free body diagram for section A-A.

The proposed methodology (Smith and Alexander 2017) for assessing the presence of trunnion friction relies on the assumption that the end-frames resist the frictional moment primarily through the axial stiffness of the truss members, or truss-action. This assumption implies that the flexural and shear contributions to the global stiffness are negligible. If the assumption of dominant truss-action holds and a truss idealization of the end-frames is statically stable, then simply solving equilibrium equations on a free body diagram (Figure 1b) may lead to an estimate of the frictional moment at the trunnion.

The proposed methodology has the benefit of requiring a small number of sensors, resulting in a low-cost monitoring scheme. This scheme consists of installing a single strain gage on any member along a section-cut, such as section A-A or section B-B shown in Figure 1a, which has an axial component that acts to resist a rotational moment at the trunnion hub. Essentially, any member along the section cut that does not have a line along its longitudinal axis that intersects a line through the trunnion hub axis will be instrumented with a single axis strain gage. This strain gage will measure longitudinal (axial) strain in that member and will be placed in a location that should provide a reasonable estimate of the average axial strain at that member cross section. For an I-shaped beam-column at a cross section sufficiently far away from any discontinuities, implying a linear distribution of strain, the strain gage can reasonably be located at the centerline of either face of the web plate. For many Tainter gate end-frames, this means that only two strain gages on each side of the gate are required to estimate the frictional moment at the trunnions. It is preferred that this section-cut be through the fully triangulated truss panels farthest from the trunnion hubs to minimize effects from flexural continuity. For example, in Figure 1a, section B$\mathrm{B}$ is preferred to section A-A.

An example of the computations required to estimate this frictional moment can be constructed from Figure $1 \mathrm{~b}$ for section A-A. If $M$ is the frictional moment at the trunnion hub, it must equilibrate with all internal forces that cause rotational moments. Equilibrium requires that an estimate of $M$ is the following:

$$
M=P_{1} L_{1}+P_{2} L_{2}
$$

where $L_{i}$ is the moment arm length from the trunnion axis to the truss member $I$, and $P_{i}$ is the axial force in truss member $i$. 
The knowledge that $M$ is beginning to approach some allowable operational threshold, perhaps based on a coefficient of friction or design limit state, will provide valuable information for maintenance planning. Once allowable thresholds are determined by engineers knowledgeable of the project, actions may be taken to maintain, refurbish, or replace trunnion hardware, likely preventing a structure from reaching a stress state that may lead to a catastrophic condition.

This methodology for measuring trunnion frictional moments has been rigorously modeled numerically and physically and has been shown to provide reasonable (within 10\%) estimates of the exact frictional moments. The numerical modeling and physical testing included trusses with all-welded joints of extremely large relative sizes to explore the contributions to stiffness imparted by flexural continuity and finite joint size. Even with unreasonably large joints, the accuracy of the methodology was within $10 \%$, which is more than adequate for decisions about preventative activities. Accuracy is improved by placing strain gages on the diagonal truss members in the panels farthest from the trunnion hub, minimizing errors from flexural continuity.

Screening. Because navigation spillway gates are operated regularly, they are better candidates for continuous real-time monitoring than those at flood control dams that are not exercised often. Friction occurs during motion, and gates that are exercised infrequently will not produce enough opportunities for measurement to warrant an in situ, real-time monitoring system. Also, based on discussions with USACE subject-matter experts, spillway gates may pose more significant risk to navigability than other types of failure consequences. Therefore, only navigation dams were considered for monitoring in this effort. However, these same methods can be used to design an on-demand trunnion friction monitoring technique for those gates that are moved infrequently.

All Tainter spillway gate subcomponents were extracted from the USACE Asset Management Operational Risk Assessment (ORA) database, along with the corresponding district, project name, latest Operational Condition Assessment (OCA) ratings, component and group ID numbers, and the assumed shipper-carrier costs associated with gate failure. These data were obtained through USACE Headquarters Asset Management.

Once the data were collected, gates and projects were removed from consideration that have $\$ 0$ of Shipper-Carrier costs (SCC) or no recorded SCC value. The SCC values in the ORA tool are derived from the SCC model, which is updated annually by the USACE Planning Center of Expertise for Inland Navigation. Also, to simplify computations, all OCA ratings with "+" or "--" were changed to the base rating (e.g., "B-" became "B"). Finally, due to an observation that there is a very short period of time, on average, between an " $\mathrm{F}$ " rating and " $\mathrm{CF}$," all "CF" ratings were changed to "F."

Each gate is composed of up to seven multiple subcomponents: (1) right end-frames, (2) left endframes, (3) right hub assemblies, (4) left hub assemblies, (5) skin plate assemblies, (6) horizontal girders, and (7) vertical girders. Only the end-frames and hub assemblies were considered to be at risk of strength-related failures due to trunnion friction. For each of these four subcomponents, the worst OCA rating of the four was assigned to the gate. This OCA rating was used to determine the likelihood that the gate will fail in each year from 0 to 10 years forward.

This was accomplished assuming the gate failure probability can be described by a Weibull distribution with a shape parameter of 3.8 and a scale parameter of 85 , corresponding to Curve 
\#19 in the ORA tool. Curve \#19 is used in the ORA tool for various types of dam gates. Each OCA rating was assumed to imply an effective age according to Table 1 below. For each of the 10 years, the component was assumed to age by 1 year. The likelihood of failure, given the component is a certain age and has not failed up to that year, was computed using Bayes rule.

\begin{tabular}{|c|c|}
\hline \multicolumn{2}{|c|}{$\begin{array}{l}\text { Table 1. Assumed gate age for OCA } \\
\text { rating. }\end{array}$} \\
\hline OCA Rating & Assumed Age in Years \\
\hline $\mathrm{A}$ & 20 \\
\hline B & 40 \\
\hline $\mathrm{C}$ & 59 \\
\hline $\mathrm{D}$ & 74 \\
\hline $\mathrm{F}$ & 111 \\
\hline
\end{tabular}

For each project and for each year from 1 to 10, the likelihood that at least one gate failed during that year was computed. Then, an event tree was constructed showing the likelihood of gates failing somewhere along the dam for each year. The SCC costs were used in this event tree, with a $3 \%$ discount rate for future years, to estimate the annual expected risk. Finally, the total risk was computed over the next 10-year period for each project.

This process was repeated with an assumption that the original design of the Tainter gates did not consider trunnion friction as a load case. The likelihood of failure was assumed to increase above the current expected value by a factor of 3 . From a structural reliability standpoint, a not unrealistic reduction of a reliability index from 2.5 to 2.1 corresponds to an increase in probability of failure by a factor of 3 (assuming a normally distributed limit state). The actual reliability index for trunnion friction here is unknown, but the magnitude of change in probability of failure seems reasonable. The total risk associated with gates that are not designed for trunnion friction was computed in the same manner as above.

The initial costs of monitoring were estimated at base of $\$ 75,000$ for the project, plus an additional $\$ 25,000$ per gate. The annual average maintenance was assumed to be $\$ 8,000$, and the net present value of the subsequent 9 years of annual maintenance, discounted at a rate of $3 \%$, was computed as $\$ 62,289$.

The net benefit from monitoring trunnion friction on all gates at a project was computed as the difference in risk of gates designed for friction and not designed for friction, subtracting the initial installation costs and discounted annual maintenance over 10 years. Projects that show a net benefit of over $\$ 100,000$ over 10 years are included for monitoring. $\$ 100,000$ is considered a reasonable amount for procurement costs, overhead, design labor, and operation and maintenance labor. The exact numbers at a particular project should be estimated at the project level.

RESULTS: The described methodology is applied to 100 projects. To further clarify the process, the methodology is described in detail for the Dresden Island project.

Example Risk Computation. Dresden Island lock in USACE District, Rock Island, has nine tainter gates. The gate ratings are three A's, two B's, two C's, and two D's. Using ORA curve 19, with a shape parameter of 3.8 and a scale parameter of 85 , the cumulative probability of failure for 
each gate was computed at each year, starting with those ages in Table 1 and increasing by 1 year each year for 10 years. Table 2 shows these values. The equation for the cumulative probability at age $\mathrm{X}$ of a Weibull distribution with these particular parameters is the following:

$$
1-e^{-\left(\frac{x}{85}\right)^{3.8}}
$$

\begin{tabular}{|c|c|c|c|c|c|c|c|}
\hline \multicolumn{2}{|c|}{ OCA A } & \multicolumn{2}{|c|}{ OCA B } & \multicolumn{2}{|c|}{ OCA C } & \multicolumn{2}{|c|}{ OCA D } \\
\hline Age & Prob. & Age & Prob. & Age & Prob. & Age & Prob. \\
\hline 20 & 0.004085 & 40 & 0.055426 & 59 & 0.220978 & 74 & 0.446002 \\
\hline 21 & 0.004916 & 41 & 0.06071 & 60 & 0.233702 & 75 & 0.462862 \\
\hline 22 & 0.005863 & 42 & 0.066334 & 61 & 0.246812 & 76 & 0.479821 \\
\hline 23 & 0.006938 & 43 & 0.072309 & 62 & 0.260297 & 77 & 0.49685 \\
\hline 24 & 0.008151 & 44 & 0.078644 & 63 & 0.274147 & 78 & 0.513922 \\
\hline 25 & 0.009513 & 45 & 0.085347 & 64 & 0.288348 & 79 & 0.531006 \\
\hline 26 & 0.011033 & 46 & 0.092427 & 65 & 0.302889 & 80 & 0.548074 \\
\hline 27 & 0.012724 & 47 & 0.099891 & 66 & 0.317752 & 81 & 0.565095 \\
\hline 28 & 0.014596 & 48 & 0.107747 & 67 & 0.332922 & 82 & 0.58204 \\
\hline 29 & 0.01666 & 49 & 0.115999 & 68 & 0.34838 & 83 & 0.598879 \\
\hline 30 & 0.018929 & 50 & 0.124654 & 69 & 0.364107 & 84 & 0.615582 \\
\hline
\end{tabular}

Bayes rule is used to find the likelihood, in each year, that a gate with the assumed age fails, given that it has not failed previously. The equation used is the following:

$$
\mathrm{P}[T \leq j+1 \mid T>j]=\frac{\operatorname{CDF}(j+1)-\operatorname{CDF}(j)}{1-\operatorname{CDF}(j)}
$$

where $\mathrm{P}$ is probability, $T$ is the age of failure, $j$ is the age at the beginning of the period of consideration, and CDF is the probability from the cumulative distribution function evaluated at

\begin{tabular}{|c|c|c|c|c|}
\hline Year & OCA A & OCA B & OCA C & OCA D \\
\hline 1 & 0.000834 & 0.005594 & 0.016334 & 0.030433 \\
\hline 2 & 0.000952 & 0.005988 & 0.017108 & 0.031573 \\
\hline 3 & 0.001082 & 0.006399 & 0.017904 & 0.032738 \\
\hline 4 & 0.001221 & 0.006828 & 0.018723 & 0.03393 \\
\hline 5 & 0.001372 & 0.007275 & 0.019566 & 0.035148 \\
\hline 6 & 0.001535 & 0.007741 & 0.020432 & 0.036392 \\
\hline 7 & 0.001709 & 0.008225 & 0.021321 & 0.037664 \\
\hline 8 & 0.001896 & 0.008727 & 0.022235 & 0.038962 \\
\hline 9 & 0.002095 & 0.009249 & 0.023173 & 0.040288 \\
\hline 10 & 0.002307 & 0.00979 & 0.024135 & 0.041641 \\
\hline
\end{tabular}
age $j$. Table 3 shows these results for each OCA rating. 
In each year, the likelihood that no gate fails is computed by assuming each gate failure is independent from the others. The equation used is the following:

$$
p=\left(1-p_{A}\right)^{3}\left(1-p_{B}\right)^{2}\left(1-p_{C}\right)^{2}\left(1-p_{D}\right)^{2}
$$

where $p$ is the likelihood that no gate fails in a particular year, $p_{i}$ is the likelihood that a gate with rating $i$ will fail in that year, and the exponents are the numbers of gates with the corresponding OCA ratings. Table 4 shows the likelihood that no gate fails in each year, given that the nine gates have the particular initial OCA ratings mentioned above.

\begin{tabular}{|c|c|c|c||}
\hline \multicolumn{4}{|c|}{ Table 4. Probability that no gate fails in each year. } \\
\hline \hline Year & Probability & Year & Probability \\
\hline \hline 1 & 0.897205 & 6 & 0.87321 \\
\hline 2 & 0.892664 & 7 & 0.868023 \\
\hline 3 & 0.887994 & 8 & 0.862707 \\
\hline 4 & 0.883195 & 9 & 0.857262 \\
\hline 5 & 0.878267 & 10 & 0.851688 \\
\hline
\end{tabular}

Table 5 depicts an event tree for 10 years, showing how the expected SCC is computed for each year. Using the tree to compute the expected SCC, the total baseline risk is computed to be $\$ 1,621,071$ over the next 10 years. This process was repeated assuming the values in Table 3 were increased by a multiple of 3 to account for gates not being designed for trunnion friction. The resulting risk was computed as $\$ 2,272,150$.

The costs of monitoring are $\$ 75,000+(\$ 25,000 \times$ nine gates $)$ for an initial cost of $\$ 300,000$. The maintenance costs of $\$ 8,000$ per year are discounted by $3 \%$ each year over 9 subsequent years, resulting in $\$ 62,289$ total. The net benefit is computed by finding the difference between baseline risk and that of gates not designed for trunnion friction, subtracting the initial and maintenance costs of monitoring. The final net benefit for Dresden Island is \$288,790. 


\begin{tabular}{|c|c|c|c|c|}
\hline \multirow[b]{2}{*}{ Year } & \multicolumn{2}{|c|}{ No failure (1-p) } & \multicolumn{2}{|c|}{ Failure $(p)$} \\
\hline & Prob. & SCC & Prob. & SCC \\
\hline 1 & 0.897205 & 0 & 0.102795 & $\$ 2,452,964$ \\
\hline 2 & 0.892664 & 0 & 0.107336 & $\$ 2,381,518$ \\
\hline 3 & 0.887994 & 0 & 0.112006 & $\$ 2,312,154$ \\
\hline 4 & 0.883195 & 0 & 0.116805 & $\$ 2,244,810$ \\
\hline 5 & $\begin{array}{c}\downarrow \\
0.878267\end{array}$ & 0 & 0.121733 & $\$ 2,179,427$ \\
\hline 6 & 0.87321 & 0 & 0.12679 & $\$ 2,115,948$ \\
\hline 7 & 0.868023 & 0 & 0.131977 & $\$ 2,054,319$ \\
\hline 8 & $\begin{array}{c}\downarrow \\
0.862707\end{array}$ & 0 & 0.137293 & $\$ 1,994,484$ \\
\hline 9 & $\begin{array}{c}\downarrow \\
0.857262\end{array}$ & 0 & 0.142738 & $\$ 1,936,392$ \\
\hline 10 & 0.851688 & 0 & 0.148312 & $\$ 1,879,993$ \\
\hline
\end{tabular}

Screening Results. The described methodology's application to 100 projects is shown in Appendix A. The screening process yields 36 projects for which there is a net benefit for implementing trunnion rod testing

FURTHER ACTIONS: The 36 projects that are selected require further screening that is difficult at the national level. The trunnion friction testing methodology is only applicable to certain gate geometries, and the risk computations assume buying down risk for gates that were not designed for trunnion friction. The following questionnaire is recommended to determine applicability of monitoring at each of the 36 identified sites:

1. Are the Tainter gate end-frames at the project composed of fully triangulated trusses, even if the members are joined via welded connection? If yes, continue. If no, done. Not applicable. 
2. Do the gate end-frames have welded, riveted, or bolted armor plates surrounding one or both sides of the trusses? If no, continue. If yes, done. Not applicable.

3. Are there any known or suspected trunnion friction issues in any gates at the project? If yes, monitoring is recommended. If no, continue.

4. Was trunnion friction explicitly considered in the design of the Tainter gates? If no, monitoring is recommended. If yes, continue.

5. Are approved emergency bulkheads or stoplogs available for rapid closure of a spillway gate in the event of a failure to prevent loss of pool? If no, monitoring is recommended. If yes, continue.

6. Can the project be acceptably managed and remain fully operable, maintaining pool for navigation and other requirements, if a single gate is inoperable and blocked with emergency bulkheads or stoplogs? If no, monitoring is recommended. If yes, no action required.

The purchase and installation of a trunnion friction monitoring system by a contractor or ERDC is estimated to be a base of $\$ 75,000$ plus an additional $\$ 25,000$ per gate. This does not include costs of contracting, site access, or annual monitoring/maintenance.

POINT OF CONTACT: The point of contact for technical inquiries regarding this USACE Coastal and Hydraulics Engineering Technical Note (CHETN) is Dr. Matthew D. Smith, U.S. Army Engineer Research and Development Center (ERDC), Coastal and Hydraulics Laboratory (CHL), Vicksburg, MS. Dr. Smith may be contacted by email at Matthew.D.Smith@erdc.dren.mil or by phone at 601-634-7429.

This CHETN should be cited as follows:

Smith, Matthew D., and Travis B. Fillmore. 2018. Methodology Supporting Civil Works Implementation of Tainter Gate Trunnion Friction Structural Health Monitoring. ERDC/CHL CHETN-IX-47. Vicksburg, MS: U.S. Army Engineer Research and Development Center. http://dx.doi.org/10.21079/11681/29975

\section{REFERENCE}

Smith, M. D., and Q. G. Alexander. 2017. SHM application to USACE large civil infrastructure: Development of trunnion friction detection methodology for radial (Tainter) gates. In Proceedings, International Workshop on Structural Health Monitoring. Stanford, CA.

NOTE: The contents of this technical note are not to be used for advertising, publication, or promotional purposes. Citation of trade names does not constitute an official endorsement or approval of the use of such products. 
Appendix A: Risk-informed project ranking for trunnion rod testing benefits. 


\begin{tabular}{|c|c|c|c|c|c|c|c|c|}
\hline Rank & District & ProjName & NumGates & Risk_10yr & Risk_NoFricDesign & CostInitial & CostAnnual & NetBenefit \\
\hline 1 & St. Louis & Melvin Price & 9 & $\$ 3,389,035$ & $\$ 6,157,791$ & $\$ 300,000$ & $\$ 62,289$ & $\$ 2,406,468$ \\
\hline 2 & Louisville & Newburgh Lock and Dam & 9 & $\$ 3,352,760$ & $\$ 6,091,882$ & $\$ 300,000$ & $\$ 62,289$ & $\$ 2,376,832$ \\
\hline 3 & Louisville & Smithland Lock and Dam & 11 & $\$ 5,993,487$ & $\$ 8,018,359$ & $\$ 350,000$ & $\$ 62,289$ & $\$ 1,612,583$ \\
\hline 4 & Louisville & John T. Myers Lock and Dam & 10 & $\$ 6,881,562$ & $\$ 8,343,059$ & $\$ 325,000$ & $\$ 62,289$ & $\$ 1,074,208$ \\
\hline 5 & Huntington & Belleville Lock and Dam & 8 & $\$ 1,486,337$ & $\$ 2,818,958$ & $\$ 275,000$ & $\$ 62,289$ & $\$ 995,332$ \\
\hline 6 & Huntington & Racine Lock and Dam & 8 & $\$ 1,460,818$ & $\$ 2,770,558$ & $\$ 275,000$ & $\$ 62,289$ & $\$ 972,452$ \\
\hline 7 & Rock Island & Lock No. 22 & 10 & $\$ 1,756,064$ & $\$ 3,065,860$ & $\$ 325,000$ & $\$ 62,289$ & $\$ 922,508$ \\
\hline 8 & Louisville & McAlpine Lock and Dam & 9 & $\$ 5,633,714$ & $\$ 6,871,394$ & $\$ 300,000$ & $\$ 62,289$ & $\$ 875,391$ \\
\hline 9 & Huntington & Willow Island Lock and Dam & 8 & $\$ 1,321,527$ & $\$ 2,506,382$ & $\$ 275,000$ & $\$ 62,289$ & $\$ 847,566$ \\
\hline 10 & Pittsburgh & Hannibal Lock and Dam & 8 & $\$ 1,268,110$ & $\$ 2,405,072$ & $\$ 275,000$ & $\$ 62,289$ & $\$ 799,673$ \\
\hline 11 & St. Paul & Lock No. 10 & 8 & $\$ 1,258,644$ & $\$ 2,387,119$ & $\$ 275,000$ & $\$ 62,289$ & $\$ 791,187$ \\
\hline 12 & Rock Island & Lock No. 12 & 7 & $\$ 1,046,944$ & $\$ 2,079,073$ & $\$ 250,000$ & $\$ 62,289$ & $\$ 719,841$ \\
\hline 13 & St. Louis & Lock No. 24 & 15 & $\$ 2,488,330$ & $\$ 3,699,205$ & $\$ 450,000$ & $\$ 62,289$ & $\$ 698,586$ \\
\hline 14 & Huntington & Greenup Lock and Dam & 9 & $\$ 4,150,058$ & $\$ 5,195,960$ & $\$ 300,000$ & $\$ 62,289$ & $\$ 683,613$ \\
\hline 15 & Rock Island & Lock No. 13 & 10 & $\$ 1,397,945$ & $\$ 2,440,630$ & $\$ 325,000$ & $\$ 62,289$ & $\$ 655,397$ \\
\hline 16 & Rock Island & Starved Rock & 10 & $\$ 1,341,038$ & $\$ 2,341,279$ & $\$ 325,000$ & $\$ 62,289$ & $\$ 612,952$ \\
\hline 17 & Rock Island & Lock No. 18 & 14 & $\$ 2,075,094$ & $\$ 3,170,866$ & $\$ 425,000$ & $\$ 62,289$ & $\$ 608,482$ \\
\hline 18 & St. Louis & Lock No. 25 & 14 & $\$ 2,057,926$ & $\$ 3,144,632$ & $\$ 425,000$ & $\$ 62,289$ & $\$ 599,417$ \\
\hline 19 & St. Paul & Lock No. 9 & 8 & $\$ 976,372$ & $\$ 1,851,768$ & $\$ 275,000$ & $\$ 62,289$ & $\$ 538,107$ \\
\hline 20 & Rock Island & Lock No. 16 & 15 & $\$ 2,125,639$ & $\$ 3,160,021$ & $\$ 450,000$ & $\$ 62,289$ & $\$ 522,093$ \\
\hline 21 & Rock Island & Lock No. 14 & 13 & $\$ 1,660,685$ & $\$ 2,614,034$ & $\$ 400,000$ & $\$ 62,289$ & $\$ 491,061$ \\
\hline 22 & Rock Island & Lock No. 11 & 13 & $\$ 1,622,042$ & $\$ 2,553,208$ & $\$ 400,000$ & $\$ 62,289$ & $\$ 468,877$ \\
\hline 23 & Louisville & Cannelton Lock And Dam & 12 & $\$ 5,740,864$ & $\$ 6,634,401$ & $\$ 375,000$ & $\$ 62,289$ & $\$ 456,248$ \\
\hline 24 & Rock Island & Marseilles & 11 & $\$ 1,238,969$ & $\$ 2,084,261$ & $\$ 350,000$ & $\$ 62,289$ & $\$ 433,004$ \\
\hline 25 & Rock Island & Lock No. 17 & 8 & $\$ 2,530,816$ & $\$ 3,296,162$ & $\$ 275,000$ & $\$ 62,289$ & $\$ 428,057$ \\
\hline 26 & St. Paul & Lock No. 8 & 10 & $\$ 1,078,127$ & $\$ 1,882,270$ & $\$ 325,000$ & $\$ 62,289$ & $\$ 416,854$ \\
\hline 27 & Mobile & Coffeeville & 8 & $\$ 824,304$ & $\$ 1,563,360$ & $\$ 275,000$ & $\$ 62,289$ & $\$ 401,766$ \\
\hline 28 & St. Paul & Lock No. 6 & 10 & $\$ 1,052,737$ & $\$ 1,837,943$ & $\$ 325,000$ & $\$ 62,289$ & $\$ 397,917$ \\
\hline 29 & St. Paul & Lock No. 7 & 11 & $\$ 1,093,965$ & $\$ 1,840,328$ & $\$ 350,000$ & $\$ 62,289$ & $\$ 334,074$ \\
\hline 30 & Rock Island & Dresden Island & 9 & $\$ 1,621,071$ & $\$ 2,272,150$ & $\$ 300,000$ & $\$ 62,289$ & $\$ 288,790$ \\
\hline 31 & Huntington & Cpt. Anthony Meldahl Lock & 12 & $\$ 4,453,016$ & $\$ 5,146,105$ & $\$ 375,000$ & $\$ 62,289$ & $\$ 255,801$ \\
\hline 32 & Mobile & Armistead I. Selden & 6 & $\$ 1,176,623$ & $\$ 1,707,472$ & $\$ 225,000$ & $\$ 62,289$ & $\$ 243,560$ \\
\hline 33 & Pittsburgh & Pike Island Lock and Dam & 9 & $\$ 2,047,805$ & $\$ 2,625,400$ & $\$ 300,000$ & $\$ 62,289$ & $\$ 215,306$ \\
\hline 34 & Rock Island & Lagrange & 1 & $\$ 162,926$ & $\$ 458,690$ & $\$ 100,000$ & $\$ 62,289$ & $\$ 133,476$ \\
\hline
\end{tabular}


ERDC/CHL CHETN-IX-47

November 2018

\begin{tabular}{|c|c|c|c|c|c|c|c|c|}
\hline 35 & Pittsburgh & Braddock Locks and Dam 02 & 4 & $\$ 278,036$ & $\$ 646,726$ & $\$ 175,000$ & $\$ 62,289$ & $\$ 131,401$ \\
\hline 36 & Pittsburgh & New Cumberland Lock and Dam & 11 & $\$ 2,154,965$ & $\$ 2,686,335$ & $\$ 350,000$ & $\$ 62,289$ & $\$ 119,081$ \\
\hline 37 & Tulsa & Newt Graham Lock & 3 & $\$ 208,242$ & $\$ 514,260$ & $\$ 150,000$ & $\$ 62,289$ & $\$ 93,729$ \\
\hline 38 & Rock Island & Peoria & 1 & $\$ 139,171$ & $\$ 391,814$ & $\$ 100,000$ & $\$ 62,289$ & $\$ 90,354$ \\
\hline 39 & St. Paul & Lock No. $5 \mathrm{a}$ & 5 & $\$ 1,390,567$ & $\$ 1,742,109$ & $\$ 200,000$ & $\$ 62,289$ & $\$ 89,253$ \\
\hline 40 & Tulsa & Chouteau & 3 & $\$ 196,546$ & $\$ 485,377$ & $\$ 150,000$ & $\$ 62,289$ & $\$ 76,542$ \\
\hline 41 & Pittsburgh & Charleroi Lock and Dam & 5 & $\$ 260,606$ & $\$ 573,055$ & $\$ 200,000$ & $\$ 62,289$ & $\$ 50,160$ \\
\hline 42 & Mobile & Howell Heflin & 5 & $\$ 238,887$ & $\$ 525,295$ & $\$ 200,000$ & $\$ 62,289$ & $\$ 24,120$ \\
\hline 43 & Little Rock & COL Maynard & 15 & $\$ 1,073,268$ & $\$ 1,595,543$ & $\$ 450,000$ & $\$ 62,289$ & $\$ 9,986$ \\
\hline 44 & Little Rock & Murray & 14 & $\$ 924,577$ & $\$ 1,412,807$ & $\$ 425,000$ & $\$ 62,289$ & $\$ 942$ \\
\hline 45 & Mobile & Bevill & 4 & $\$ 176,223$ & $\$ 409,904$ & $\$ 175,000$ & $\$ 62,289$ & $(\$ 3,608)$ \\
\hline 46 & Huntington & Winfield Lock - New Lock - Gate & 1 & $\$ 80,597$ & $\$ 226,907$ & $\$ 100,000$ & $\$ 62,289$ & $(\$ 15,979)$ \\
\hline 47 & Mobile & Holt Lock and Dam & 14 & $\$ 879,644$ & $\$ 1,344,148$ & $\$ 425,000$ & $\$ 62,289$ & $(\$ 22,785)$ \\
\hline 48 & Mobile & Amory & 4 & $\$ 160,022$ & $\$ 372,220$ & $\$ 175,000$ & $\$ 62,289$ & $(\$ 25,091)$ \\
\hline 49 & Mobile & Fulton & 4 & $\$ 155,796$ & $\$ 362,389$ & $\$ 175,000$ & $\$ 62,289$ & $(\$ 30,695)$ \\
\hline 50 & Mobile & Stennis & 5 & $\$ 466,418$ & $\$ 686,537$ & $\$ 200,000$ & $\$ 62,289$ & $(\$ 42,170)$ \\
\hline 51 & Mobile & Montgomery & 5 & $\$ 180,608$ & $\$ 397,146$ & $\$ 200,000$ & $\$ 62,289$ & $(\$ 45,752)$ \\
\hline 52 & Mobile & Rankin & 3 & $\$ 112,899$ & $\$ 278,808$ & $\$ 150,000$ & $\$ 62,289$ & $(\$ 46,380)$ \\
\hline 53 & Mobile & Aberdeen & 6 & $\$ 219,204$ & $\$ 457,287$ & $\$ 225,000$ & $\$ 62,289$ & $(\$ 49,207)$ \\
\hline 54 & Little Rock & Arthur V. Ormond & 14 & $\$ 826,681$ & $\$ 1,263,217$ & $\$ 425,000$ & $\$ 62,289$ & $(\$ 50,753)$ \\
\hline 55 & Nashville & Cheatham Lock and Dam & 7 & $\$ 232,112$ & $\$ 460,940$ & $\$ 250,000$ & $\$ 62,289$ & $(\$ 83,461)$ \\
\hline 56 & Little Rock & James W. Trimble & 15 & $\$ 858,948$ & $\$ 1,276,930$ & $\$ 450,000$ & $\$ 62,289$ & $(\$ 94,307)$ \\
\hline 57 & Rock Island & Lock No. 21 & 10 & $\$ 3,334,202$ & $\$ 3,626,775$ & $\$ 325,000$ & $\$ 62,289$ & $(\$ 94,716)$ \\
\hline 58 & Little Rock & David D. Terry & 17 & $\$ 1,109,651$ & $\$ 1,570,682$ & $\$ 500,000$ & $\$ 62,289$ & $(\$ 101,258)$ \\
\hline 59 & Vicksburg & John H. Overton & 5 & $\$ 130,037$ & $\$ 285,942$ & $\$ 200,000$ & $\$ 62,289$ & $(\$ 106,384)$ \\
\hline 60 & Little Rock & Emmett Sanders & 17 & $\$ 1,224,396$ & $\$ 1,672,919$ & $\$ 500,000$ & $\$ 62,289$ & $(\$ 113,767)$ \\
\hline 61 & Louisville & Markland Lock and Dam & 12 & $\$ 5,722,207$ & $\$ 6,043,338$ & $\$ 375,000$ & $\$ 62,289$ & $(\$ 116,158)$ \\
\hline 62 & Little Rock & Toad Suck Ferry & 16 & $\$ 918,392$ & $\$ 1,330,974$ & $\$ 475,000$ & $\$ 62,289$ & $(\$ 124,707)$ \\
\hline 63 & St. Paul & Lower St. Anthony Falls & 3 & $\$ 55,664$ & $\$ 137,464$ & $\$ 150,000$ & $\$ 62,289$ & $(\$ 130,489)$ \\
\hline 64 & Seattle & Hiram M. Chittenden & 6 & $\$ 335,597$ & $\$ 487,005$ & $\$ 225,000$ & $\$ 62,289$ & $(\$ 135,880)$ \\
\hline 65 & St. Louis & Kaskaskia & 2 & $\$ 40,085$ & $\$ 85,554$ & $\$ 125,000$ & $\$ 62,289$ & $(\$ 141,820)$ \\
\hline 66 & Pittsburgh & Maxwell Lock and Dam & 5 & $\$ 507,829$ & $\$ 624,479$ & $\$ 200,000$ & $\$ 62,289$ & $(\$ 145,639)$ \\
\hline 67 & Little Rock & Joe Hardin & 18 & $\$ 1,198,239$ & $\$ 1,606,020$ & $\$ 525,000$ & $\$ 62,289$ & $(\$ 179,508)$ \\
\hline 68 & Jacksonville & Ortona & 2 & $\$ 567$ & $\$ 1,492$ & $\$ 125,000$ & $\$ 62,289$ & $(\$ 186,364)$ \\
\hline 69 & St. Paul & Lock No. 2 & 19 & $\$ 1,176,092$ & $\$ 1,596,216$ & $\$ 550,000$ & $\$ 62,289$ & $(\$ 192,165)$ \\
\hline 70 & Mobile & Wilkins & 11 & $\$ 312,472$ & $\$ 525,658$ & $\$ 350,000$ & $\$ 62,289$ & $(\$ 199,103)$ \\
\hline 71 & Vicksburg & Felsenthal & 3 & $\$ 1,750$ & $\$ 3,609$ & $\$ 150,000$ & $\$ 62,289$ & $(\$ 210,430)$ \\
\hline 72 & Vicksburg & H.K. Thatcher & 3 & $\$ 790$ & $\$ 1,381$ & $\$ 150,000$ & $\$ 62,289$ & $(\$ 211,698)$ \\
\hline
\end{tabular}


ERDC/CHL CHETN-IX-47

November 2018

\begin{tabular}{|c|c|c|c|c|c|c|c|c|}
\hline 73 & Vicksburg & Russell B. Long & 5 & $\$ 40,541$ & $\$ 89,146$ & $\$ 200,000$ & $\$ 62,289$ & $(\$ 213,683)$ \\
\hline 74 & Vicksburg & Joe D. Waggonner & 5 & $\$ 82,614$ & $\$ 129,005$ & $\$ 200,000$ & $\$ 62,289$ & $(\$ 215,897)$ \\
\hline 75 & Vicksburg & Columbia & 4 & $\$ 16,101$ & $\$ 37,453$ & $\$ 175,000$ & $\$ 62,289$ & $(\$ 215,937)$ \\
\hline 76 & Pittsburgh & Point Marion Lock and Dam & 6 & $\$ 54,594$ & $\$ 113,891$ & $\$ 225,000$ & $\$ 62,289$ & $(\$ 227,993)$ \\
\hline 77 & New Orleans & Calcasieu Barrier & 5 & $\$ 25,365$ & $\$ 55,776$ & $\$ 200,000$ & $\$ 62,289$ & $(\$ 231,878)$ \\
\hline 78 & Vicksburg & Lock and Dam No. 3 & 6 & $\$ 50,573$ & $\$ 105,502$ & $\$ 225,000$ & $\$ 62,289$ & $(\$ 232,360)$ \\
\hline 79 & Vicksburg & Jonesville & 5 & $\$ 114,528$ & $\$ 143,482$ & $\$ 200,000$ & $\$ 62,289$ & $(\$ 233,336)$ \\
\hline 80 & Pittsburgh & Opekiska Lock and Dam & 4 & $\$ 134$ & $\$ 245$ & $\$ 175,000$ & $\$ 62,289$ & $(\$ 237,178)$ \\
\hline 81 & Walla Walla & Lower Monumental & 8 & $\$ 95,877$ & $\$ 181,839$ & $\$ 275,000$ & $\$ 62,289$ & $(\$ 251,327)$ \\
\hline 82 & Walla Walla & Little Goose & 8 & $\$ 86,797$ & $\$ 164,617$ & $\$ 275,000$ & $\$ 62,289$ & $(\$ 259,468)$ \\
\hline 83 & St. Paul & Lock No. 4 & 22 & $\$ 1,452,219$ & $\$ 1,871,074$ & $\$ 625,000$ & $\$ 62,289$ & $(\$ 268,434)$ \\
\hline 84 & Little Rock & Dardanelle & 20 & $\$ 1,106,490$ & $\$ 1,473,934$ & $\$ 575,000$ & $\$ 62,289$ & $(\$ 269,844)$ \\
\hline 85 & Tulsa & W.D. Mayo & 12 & $\$ 1,204,239$ & $\$ 1,371,616$ & $\$ 375,000$ & $\$ 62,289$ & $(\$ 269,912)$ \\
\hline 86 & Pittsburgh & Morgantown Lock and Dam & 6 & $\$ 5,631$ & $\$ 11,747$ & $\$ 225,000$ & $\$ 62,289$ & $(\$ 281,173)$ \\
\hline 87 & Walla Walla & Ice Harbor & 10 & $\$ 139,498$ & $\$ 243,545$ & $\$ 325,000$ & $\$ 62,289$ & $(\$ 283,242)$ \\
\hline 88 & Walla Walla & Lower Granite & 8 & $\$ 55,565$ & $\$ 105,383$ & $\$ 275,000$ & $\$ 62,289$ & $(\$ 287,471)$ \\
\hline 89 & Jacksonville & St. Lucie & 7 & $\$ 2,363$ & $\$ 4,693$ & $\$ 250,000$ & $\$ 62,289$ & $(\$ 309,959)$ \\
\hline 90 & Vicksburg & Lindy Claiborne Boggs & 11 & $\$ 409,282$ & $\$ 499,014$ & $\$ 350,000$ & $\$ 62,289$ & $(\$ 322,557)$ \\
\hline 91 & Tulsa & Webbers Falls & 12 & $\$ 1,114,267$ & $\$ 1,209,859$ & $\$ 375,000$ & $\$ 62,289$ & $(\$ 341,697)$ \\
\hline 92 & Little Rock & Lock Num. 2 \& Mills Dam & 16 & $\$ 1,734,123$ & $\$ 1,921,751$ & $\$ 475,000$ & $\$ 62,289$ & $(\$ 349,661)$ \\
\hline 93 & Mobile & R. F. Henry & 11 & $\$ 179$ & $\$ 301$ & $\$ 350,000$ & $\$ 62,289$ & $(\$ 412,167)$ \\
\hline 94 & Little Rock & Ozark-Jeta Taylor & 15 & $\$ 1,228,516$ & $\$ 1,302,007$ & $\$ 450,000$ & $\$ 62,289$ & $(\$ 438,797)$ \\
\hline 95 & Tulsa & Robert S. Kerr & 18 & $\$ 1,242,492$ & $\$ 1,314,789$ & $\$ 525,000$ & $\$ 62,289$ & $(\$ 514,992)$ \\
\hline 96 & St. Paul & Lock No. 5 & 28 & $\$ 1,548,495$ & $\$ 1,852,503$ & $\$ 775,000$ & $\$ 62,289$ & $(\$ 533,281)$ \\
\hline 97 & Mobile & Millers Ferry & 17 & $\$ 286$ & $\$ 404$ & $\$ 500,000$ & $\$ 62,289$ & $(\$ 562,170)$ \\
\hline 98 & Rock Island & Brandon Road & 21 & $\$ 1,513,132$ & $\$ 1,573,659$ & $\$ 600,000$ & $\$ 62,289$ & $(\$ 601,762)$ \\
\hline 99 & Portland & The Dalles & 23 & $\$ 665,977$ & $\$ 718,414$ & $\$ 650,000$ & $\$ 62,289$ & $(\$ 659,851)$ \\
\hline 100 & Rock Island & Lock No. 20 & 40 & $\$ 2,916,822$ & $\$ 3,226,727$ & $\$ 1,075,000$ & $\$ 62,289$ & $(\$ 827,384)$ \\
\hline
\end{tabular}

